\title{
Adeus, secularismo! Bem-vindo, pluralismo! Rumo a um novo paradigma da modernidade?
}

\author{
Carlos E. Freitas ${ }^{1}$
}

\section{Resenha do livro:}

BERGER, Peter. L. Os múltiplos altares da modernidade: rumo a um paradigma da religião numa época pluralista. Petrópolis, Editora Vozes, 2017.

Mais conhecido nas ciências sociais pela publicação de "A Construção social da realidade", em 1966, e de "O Dossel Sagrado: elementos para uma teoria sociológica da religião", em 1967, Peter Berger foi, juntamente com Alfred Schütz, a principal referência contemporânea da sociologia fenomenológica. Autodefinindo-se como um homem "luterano" e de "centro-direita", Berger desenvolveu importantes estudos em antropologia filosófica, sociologia do conhecimento e sociologia da religião. Seu principal legado intelectual foi na teoria social e consiste na sistematização e difusão do termo "construção social" entre os cientistas sociais. Com esse termo, Berger (2008) defendeu que o que compreendemos por realidade social é uma "construção" em curso a partir de uma dialética entre processos de institucionalização ("sociedade como realidade objetiva") e processos de interiorização ("sociedade como realidade subjetiva"). E como é sabido, dessa compreensão "construtivista" ou "construcionista" da realidade, nasceu a "problemática construtivista", uma quase unanimidade presente em

1 Programa de Pós-Graduação em Sociologia da Universidade Federal da Paraíba (UFPB) - João Pessoa Brasil - Bolsista CAPES - calfreitas@hotmail.com 
diferentes programas de investigação em sociologia. ${ }^{2}$ Nas últimas décadas, porém, Berger também se destacou no campo de estudos da sociologia da religião. Sobretudo, por sua persistente crítica da tese da secularização - na obra The Desecularization of the World: Resurgent Religion and World Politics (1999), Berger apresentou ao grande público o conteúdo mais acabado dessa crítica. Naobra aqui resenhada, ele retoma a mesma crítica da teoria da secularização e se aprofunda mais sobre o tema. Porém, à medida que avançamos na leitura, vamos tomando consciência que o secularismo não é o tema central, mas, sim, o pluralismo moderno e seus efeitos na religiosidade. Agora não se trata apenas de contestar o alcance empírico generalizado do paradigma da secularização, mas também de oferecer um paradigma alternativo que explique melhor os contornos atuais da modernidade. Posto isso, a tese geral desenvolvida ao longo da obra pode ser resumida, grosseiramente, na seguinte afirmação: o pluralismo explica melhor a configuração da modernidade e suas tendências contemporâneas do que a teoria do secularismo.

Sendo assim, na obra "Os múltiplos altares da modernidade: rumo a um paradigma da religião numa época pluralista” (2014) ${ }^{3}$ [2017], Berger inicia a discussão chamando atenção para o fato de que a "teoria da secularização" compreendida por ele como a tese fundada na ideia de que a modernização levaria ao declínio da religião - tornou-se hoje um paradigma dos estudos da religião a ser superado. Para Berger, a tese da secularização não encontra lastro empírico suficiente; ao contrário, o mundo de hoje é tão religioso quanto na era pré-moderna. Diante da constatação do déficit empírico da teoria da secularização, Berger propõe, então, um novo paradigma que seja capaz de lidar com o que ele chama de "dois pluralismos": "a coexistência de diferentes religiões" e a "coexistência de discursos religiosos e seculares" (2017: 9). Ainda sobre o pluralismo, Berger reconhece nele a "maior mudança provocada pela modernidade em relação ao lugar da religião". Porém, tratar-se-ia, na verdade, de um fenômeno "independente" da secularização. E que implicou em "desafios" para a fé religiosa, mas que "diferem" daqueles que eram creditados à secularização, adverte o sociólogo estadunidense. Assim, no estudo como um todo, Berger ambiciona apresentar o que descreve como a "construção de um novo paradigma de modernidade e religião" (Ibidem: 15). Para isso, o sociólogo e teólogo

2 Além de se constituir enquanto "problemática sociológica", a ideia de construção social da realidade também deu origem inúmeras abordagens "construcionistas" nas ciências sociais. Sobre isso, ver Corcuff (2001) e DeSousa Filho (2017).

3 Data da primeira edição publicada em inglês pela editora Walter de Gruyter GmbH \& Co. KG, com o título The Many Altars of Modernity: Toward a Paradigm for Religion in a Pluralist Age. 
austro-estadunidense organiza seis capítulos para o desenvolvimento dos argumentos gerais que sustentam sua tese. Além desses seis capítulos, completam o corpo textual da obra mais três comentários de estudiosos da religião (a saber: Nancy Ammerman, Detlef Pollack e Fenggang Yang) que se apresentam como "respostas" à tese do pluralismo defendida por Berger.

No primeiro capítulo, O fenômeno pluralista, Berger apresenta uma definição sociológica do pluralismo, suas principais características e suas consequências gerais na vida moderna. Berger define o pluralismo como "uma situação social na qual pessoas de diferentes etnias, cosmovisões e moralidades vivem juntas pacificamente e interagem amigavelmente" (Ibidem: 20). Em seguida, Berger destaca que não faz muito sentido falar de pluralismo se não há conversação entre pessoas diferentes. No pluralismo, entende Berger, deve haver "conversação constante" e o desencadeamento do que ele chama de "contaminação cognitiva” [cognitive contamination]. Isso significa considerar que na experiência de conversação contínua há a possibilidade de influência recíproca. Existindo em diferentes períodos da história humana e associado às cidades (lugares de encontro de pessoas com diferentes experiências e conhecimento), o pluralismo, na modernidade, torna-se um fenômeno globalizado. Com efeito, a modernização provoca uma enorme transformação na condição humana: "podemos admitir que a capacidade de fazer algumas escolhas é intrínseca ao homo sapiens, (...) mas o âmbito das escolhas aumentou no curso da história e aumentou exponencialmente desde a Revolução Industrial" (Ibidem: 26). Dito isso, o pluralismo é um importante fator de multiplicação das escolhas. Porém, continua Berger, a ampliação das possibilidades de escolha produz sentimentos ambíguos nos indivíduos. Se inicialmente a desinstitucionalização pode ser sentida como aumento da liberdade e autonomia para o indivíduo, posteriormente a "vertigem da liberdade" abre o caminho para uma "inquietação crescente". Diante dessa inquietação, o indivíduo agora se vê estimulado a se engajar em uma nova busca de libertação: “(...) uma libertação da antiga libertação que abolira as velhas coações institucionais” (Ibidem: 33). Nesse sentido, ao relativizar e enfraquecer as certezas com os quais as pessoas viviam anteriormente, o pluralismo acaba por transformar a certeza em uma "mercadoria escassa". E nessa busca por certeza, duas tentativas de "aliviar a inquietação trazida pela relativização" se sobressaem: o fundamentalismo e o relativismo. Descrito por Berger como um "esforço para restaurar a certeza ameaçada", o fundamentalismo aciona em sua retórica a "promessa de certeza redentora". Por sua vez, o relativismo pode ser definido como "admissão da relatividade" e constitui a cosmovisão dos modernos. 
Berger abre o segundo capítulo, Pluralismo e crença individual, com o exame dos limites do conceito de religião e insiste no seu uso, porém, mais próximo do "senso comum": "uma crença que existe uma realidade para além da realidade da experiência ordinária, e que esta realidade é de grande importância para a vida humana" (Ibidem: 48). Em seguida, Berger estabelece uma distinção entre o que considera serem dois aspectos cruciais da religião: "a religião na consciência e no comportamento dos indivíduos e a religião nas instituições coletivas” (Idem). Tratando particularmente do primeiro aspecto crucial da religião, Berger vai afirmar que, desde o Século XVIII, pensadores têm perseguido a questão sobre como a modernidade afeta a religião. Sob a influência da Revolução Francesa e do Iluminismo, intelectuais de diferentes matrizes ideológicas tentaram responder a essa questão com a "hipótese do efeito antirreligioso da modernidade". Abraçada pelos precursores das ciências sociais (Max Weber, Auguste Comte e Ėmile Durkheim), a mesma hipótese especulativa se converteu em "hipótese científica" e influenciou diferentes diagnósticos da modernidade desenvolvidos pelos clássicos. Com o passar do Século XX, no entanto, a teoria da secularização não encontrou sustentação empírica para além de alguns países europeus. Berger atribui o erro de diagnóstico à uma visão eurocêntrica do mundo e também à incompreensão sobre o fenômeno do pluralismo. Sobre esse último, acreditava-se que o pluralismo, assim como a modernização, também impulsionava a secularização. Isso posto, para compreender melhor as tendências atuais da religião no mundo, Berger vai defender que é necessário tratar modernidade, secularização e pluralismo como fenômenos distintos em termos de causalidade. Se o pluralismo, de fato, é um efeito da modernidade, o mesmo não pode ser dito sobre a secularização. A modernidade não leva, necessariamente, a uma maior secularização do mundo. O que se verifica nas sociedades modernas ocidentais e orientais, ao contrário, é muito mais um movimento de renovação das principais tradições religiosas do mundo. Nesse movimento de renovação, o cristianismo e o islamismo são "os dois principais atores no palco global".

Para Berger, o pluralismo produz efeitos também na consciência do indivíduo moderno. Seu efeito mais significativo é a tendência de fazer subir a religião do "nível da certeza até o nível da opinião". Esse nível das preferências e opiniões, diz Berger, se expressa bem num termo bastante comum da linguagem americana: "preferência religiosa" (Ibidem: 71). Logo, em expressões cotidianas como "por acaso eu sou católico", "estou no budismo agora", os americanos modernos expressam seus vínculos com a religião em termos de "escolha" e não mais de "destino". Igualmente, o pluralismo multiplica o número de "estruturas de plausibilidade" e muda mais o "como" do que o "o que" da crença (Ibidem: 74). 
O terceiro capítulo (Pluralismo e instituições religiosas) é dedicado ao exame dos modos como o pluralismo se relaciona com as instituições. Berger entende as instituições como programas de comportamento internalizados pelo indivíduo e que resultam numa agência espontânea e pré-reflexiva em conformidade com os padrões e sistemas de valores. A vida social é povoada por instituições, mas que, por sua vez, não são permanentes. Embora interiorizadas, as prescrições e proibições podem ser "desinstitucionalizadas". Enquanto o processo de institucionalização (entendido por Berger como um modo de "objetivação") resulta na produção do "mundo-dado-como-certo", os processos de desinstitucionalização "desmantelam" a "objetividade" do mesmo mundo e o torna "subjetivado". A consequência dessa subjetivação do mundo é a ampliação da liberdade de agência dos indivíduos. Sobre a especificidade da instituição religiosa, Berger destaca a regulação do comportamento na prática religiosa: "ajoelhar-se, benzer-se, tomar na mão seu rosário, dizer orações adequadas" são práticas exigidas e experimentadas no interior da religião. Mais, o não compartilhamento das "experiências extraordinárias de virtuosi" pelas massas de crentes leva a instituição religiosa a exercer duas funções fundamentais: a de "rememorar" e "domesticar" as experiências extraordinárias de virtuosi (Ibidem: 79). Contudo, também processos de desinstitucionalização ocorrem nas diferentes religiões, impulsionados principalmente pelo pluralismo. A Igreja Católica, por exemplo, inicialmente assumiu uma postura de resistência ao pluralismo. Somente depois do Concílio Vaticano II, a Igreja Católica passou a respeitar e tolerar a liberdade religiosa. Também as religiões dos EUA foram afetadas pelo pluralismo. Devido ao padrão de imigração para as colônias americanas, produziu-se um rico pluralismo religioso e, em consequência, a produção da "comunidade confessional"; esta, operando como uma "associação voluntária” e que, segundo Berger, é "a forma social típica da religião numa situação pluralista” nos EUA (Ibidem: 90). Nesse sentido, Berger entende o sistema confessional como o encontro do pluralismo religioso com a ideia de liberdade religiosa. Desse encontro, o pluralismo se difundiu como "fato empírico" acompanhado e como exigência normativa de liberdade religiosa.

No Capítulo 4 (O discurso secular), Berger investiga a origem histórica do discurso secular e o identifica no período do colapso da cosmovisão mítica do mundo, matriz comum de todas as culturas humanas passadas. Descrito pelo historiador alemão Eric Voegelin como o movimento de "compacticidade" para a "diferenciação", aquele acontecimento histórico tornou possível a emergência do discurso secular. Depois disso, o discurso secular alcançou 
rapidamente um "sucesso prático", confirmado no fato de que o mesmo habita as instituições e a consciência dos indivíduos modernos. Na modernidade, defende Berger, é possível identificar dois tipos de pluralismo: a coexistência de diferentes opções religiosas na mesma sociedade e a coexistência do discurso religioso com o discurso secular (Ibidem: 111). Com efeito, a capacidade de manipular diferentes discursos vem a ser, para Berger, um traço característico da pessoa moderna - na experiência da maioria das pessoas, a secularidade e a religião coexistem relativamente bem. Berger procura explicar essa coexistência equilibrada a partir do conceito de "realidades múltiplas" - tomado de empréstimo de Alfred Schutz. Com base nesse conceito, Berger descreve experiências religiosas intensas em contextos modernos, defende que o indivíduo moderno possui a capacidade de lidar tanto com definições religiosas quanto com definições seculares da realidade, e acrescenta que a mesma realidade se encontra diferenciada em múltiplas estruturas de relevância, o que é, acredita Berger, um aspecto chave da modernidade. Por conseguinte, ao enfraquecer a realidade dada-como-certa, o pluralismo moderno impulsiona nos indivíduos a atitude de relação reflexiva com os programas institucionais. Na modernidade, a liberdade religiosa é ao mesmo tempo uma exigência normativa e um imperativo político.

No Capítulo 5, (Religião e modernidades múltiplas), Berger recupera o conceito de "modernidades múltiplas", de Shmuel Eisenstadt, e o aplica para pensar a diversidade de formas de síntese institucional entre elementos da tradição e da modernidade. Ao refutar a ideia de versão única da modernidade, Berger acredita que o conceito de Eisenstadt permitiu visualizar "modernidades múltiplas em ação". O Japão, por exemplo, é um desses casos de "modernização seletiva" onde o processo de modernização tecnológica convive com a persistência dos valores tradicionais do xintoísmo. Além disso, Berger menciona a modernização das organizações religiosas que passam a incorporar estruturas burocráticas e princípios de gestão corporativa que são da lógica secular capitalista. Contudo, disputas de fronteiras entre o discurso religioso e o discurso secular se reproduzem em diferentes espaços institucionais, a exemplo da escola e do direito. Berger finaliza o capítulo enfatizando que o pluralismo se faz presente tanto na consciência do indivíduo quanto nas instituições e nas diferentes versões da modernidade.

Diante da constatação da presença globalizada do pluralismo, no Capítulo 6 ( $A$ administração política do pluralismo), Berger examina as diferentes estratégias políticas de administração do pluralismo religioso. Para lidar com o pluralismo religioso, as sociedades têm criado diferentes "fórmulas de paz" 
para “(...) uma coexistência pacífica entre diferentes tradições e instituições religiosas no interior de uma sociedade" (Ibidem: 158). No caso particular das sociedades islâmicas, entretanto, Berger admite que as fórmulas de administração política do pluralismo são ainda mais complexas, pois "duas subquestões distintas" se impõem dentro da questão mais fundamental da relação do Islã com a modernidade: "como administrar a coexistência entre discurso islâmico e discurso secular, e como administrar a coexistência entre diferentes tradições religiosas no interior de um Estado muçulmano" (Ibidem: 168). Berger explica a dificuldade das sociedades islâmicas em lidarem com a coexistência do discurso secular e o discurso religioso pela existência da sharia, a lei islâmica que rege tanto a esfera pública quanto os espaços mais íntimos da esfera privada. Ainda assim, de modo geral, o modelo de separação entre Igreja e Estado, defende Berger, beneficiou as minorias religiosas nas democracias ocidentais. Portanto, somente o modelo de separação entre Igreja e Estado tem se mostrado mais eficaz para lidar ao mesmo tempo com o pluralismo da coexistência entre diferentes religiões e com o pluralismo da coexistência entre o discurso secular e o discurso religioso: "nas condições modernas, é mais provável que alguma versão da separação entre Igreja e Estado venha a sustentar uma ordem política estável e humana capaz de administrar o que chamei de 'os dois pluralismos"' (Ibidem: 181). Finalmente, Berger encerra seu livro com uma defesa enfática da liberdade religiosa. Resgatando a descrição pascaliana da condição humana como ponto intermediário entre "o nada e o infinito" e assinalando que a religião tem sido o "principal veículo" de indagação sobre o sentido da vida, Berger defende a liberdade religiosa como um "direito fundamental" de perseguir questões acerca do sentido da vida humana. Nas palavras de Berger, "esta liberdade coloca um limite ao poder do Estado; ela é um direito fundamental que precede e supera a democracia ou qualquer forma particular de governo" (Ibidem: 182).

Para fundamentar teoricamente os argumentos desenvolvidos ao longo do seu livro, Berger vai se servir de diferentes fontes, mas principalmente das ideias e conceitos de Alfred Schutz, Arnold Gehlen, Max Weber, Eric Voegelin e Shmuel Eisenstadt. Na fenomenologia de Schutz, Berger vai extrair conceitos como "estrutura de relevância" e "realidades múltiplas" para compreender como as pessoas modernas lidam cotidianamente com diferentes definições da realidade social. Na antropologia filosófica de Gehlen, Berger recupera sua teoria evolutiva das instituições e os conceitos de "institucionalização" e "desinstitucionalização" para, em seguida, empregá-los dialeticamente na análise da relação que as pessoas estabelecem com as instituições modernas. Os 
conceitos de "virtuosi religiosos", "religião das massas", "comunidade confessional" e "rotinização do carisma" são tomados de empréstimo da sociologia da religião de Weber e empregados para entender a coexistência de experiências do sobrenatural com práticas seculares. Em Voegelin, Berger encontra o que acredita ser a melhor explicação para a origem histórica do discurso secular; e, finalmente, no conceito de "modernidades múltiplas", formulado por Eisenstadt, Berger vai encontrar o lastro teórico-empírico que confirmaria a coexistência do discurso secular com o discurso religioso em múltiplas experiências de modernização. E, claro, além dos conceitos sociológicos tomados de empréstimo de outros autores, Berger também aciona seus próprios conceitos ("estrutura de plausibilidade", "pacotes intrínsecos" e "pacote extrínseco") 4 já trabalhados em estudos anteriores.

De modo geral, o autor mescla uma abordagem institucionalista com uma abordagem fenomenológica, uma fórmula teórico-metodológica já conhecida pelas leitoras e leitores familiarizados com a sociologia de Berger. Com efeito, Berger se preocupa em articular em perspectiva diacrônica e de maneira dialética as dimensões "micro" (consciência individual) e "macro" (instituição religiosa) do pluralismo moderno - o que permite uma imagem mais dinâmica e variacional da relação entre indivíduo e instituição - e isso constitui um ponto alto de sua análise. Também um tópico temático interessante no estudo de Berger é sua análise das condições institucionais de realização da liberdade. Informado, sobretudo, pela antropologia de Gehlen, Berger identifica a ampliação da liberdade de ação como tendência inscrita na modernidade e potencializada pelo pluralismo. Ampliação da liberdade de ação que, segundo Berger, se verifica também na esfera religiosa.

Entrando numa avaliação mais crítica da obra, é possível destacar pelo menos quatro aspectos problemáticos no estudo de Berger. Em primeiro lugar, em sua crítica dirigida contra Charles Taylor, Berger parece não fazer justiça ao modo como este último reformula o sentido de secularização. A leitora ou leitor que desconhece a obra "Uma Era Secular" (2010) e que se fia na leitura que Berger faz da mesma pode acabar negligenciando uma ideia fundamental na versão tayloriana da tese do secularismo, qual seja, a de que existem pelos menos três sentidos possíveis para o termo secularidade: 1) a secularidade compreendida como existência da separação entre Estado e Igreja; 2) a ideia de secularidade

4 Convém assinalar que seu conceito de "dessecularização", tão importante em obras anteriores, é completamente ignorado e não chega a ser empregado em nenhum momento da análise desenvolvida no presente estudo. Uma ausência que merece reflexão pormenorizada. 
entendida como declínio e abandono de convicções e práticas religiosas; e 3) a secularidade compreendida em termos de um contexto histórico-cultural onde a fé em Deus é uma "opção" dentro da "pluralidade de opções" de "maneiras de viver e experimentar a vida moral/espiritual" (Taylor, 2010: 14-15). Na leitura da obra de Taylor, sem muito esforço de interpretação, qualquer leitora ou leitor entende que o filósofo canadense concordaria com Berger acerca do erro empírico cometido por aqueles que abraçaram o segundo sentido do secularismo. O próprio Taylor (2010: 15-25) rejeita a segunda versão do secularismo e se posiciona como um autor que emprega o termo secularismo em sua terceira acepção (ampliação da "pluralidade de opções"); e, nesse sentido, o filósofo canadense mais se aproxima do que se afasta da tese de Berger.

Um segundo aspecto problemático refere-se ao modo como Berger explica as condições de institucionalização das experiências religiosas de autotranscendência originárias. Ao se apoiar unicamente no conceito de "carisma", de Weber, para explicar aquele fenômeno, Berger acaba por reproduzir uma visão restrita e centrada nas "elites carismáticas" (santos, profetas e mágicos) como se somente estas vivenciassem experiências religiosas de autotranscendência, restando às massas de crentes apenas o acesso (mnemônico e "ritualizado") mediado pela instituição religiosa. Contra essa interpretação "elitista" e exclusivamente "institucionalista" das experiências de autotranscendência, outras investigações sociológicas (James, 2002; Joas, 2000) destacam diferentes exemplos cotidianos de experiências religiosas de autotranscendência vividas por pessoas comuns e que nem sempre estão vinculadas a uma determinada religião. Em terceiro lugar, Berger descreve o encontro entre tradições religiosas como um fator gerador de incerteza e dúvida acerca da fé, interpretação que pode ser contraposta por estudos sobre o mesmo fenômeno, desenvolvidos por autores como Max Scheler e Taylor. Nos escritos desses dois autores, o encontro entre diferentes tradições religiosas nem sempre resulta em "crises" existenciais com a tradição de origem, mas ao contrário, a experiência do contato inter-religioso pode impulsionar processos de renovação dos compromissos de fé (Scheler, 1994; Taylor, 1997).

A "crise" na crença religiosa diante do encontro inter-religioso, que em Berger é um fato tomado como certo, em Scheler e Taylor é sempre um fato empiricamente aberto. Por último, se Berger (2017: 102) acerta em sua crítica ao alcance generalizado do paradigma da "Teoria da Escolha Racional" no estudo da religião, o mesmo não leva essa crítica tão longe quanto merecia. Corretamente preocupado em demonstrar que nós, indivíduos modernos, não estabelecemos uma relação com a religiosidade apenas em termos 
de "obrigação", Berger, contudo, aceita a linguagem econômica da "escolha" para descrever a relação moderna com a religião. E aqui, mais uma vez, Berger poderia ter seguido os exemplos de autores como Èmile Durkheim (2009), Scheler (1994), Taylor (1997) e Hans Joas (2014), e procurado superar tanto os modelos utilitaristas quanto os modelos normativistas da ação, por meio do emprego de termos como "desejabilidade", "compromisso/adesão", "disposição", "atração" ou "opção" - conceitos descritores alternativos da relação entre indivíduo e instituição religiosa que evitam reduzir a orientação da ação tanto à gramática econômica ("escolha") quanto à gramática normativa ("obrigação", "regra"). Mais do que controvérsias teóricas, os quatro aspectos problemáticos que destacamos neste parágrafo, se discutidos em profundidade, podem comprometer seriamente o "novo" paradigma da modernidade proposto por Berger.

Em relação ao estilo de escrita, nesta obra as leitoras e os leitores encontram um Peter Berger ensaísta e bastante sarcástico, que não poupa munição de ironias contra intelectuais, movimentos estudantis, feministas, marxistas e outros grupos sociais. É evidente que o alvo preferencial de Berger são atores sociais comprometidos com a crítica das instituições e com a defesa de causas libertárias. E sobre isso, Berger não faz muita questão de disfarçar seu conservadorismo. Porém, suas posições ideológicas não chegam a afetar o desenvolvimento das ideias apresentadas no livro. Ao contrário, tempera com bom humor e leveza a leitura de um assunto considerado abstrato e indigesto, tal como a problemática da secularização.

Ainda sobre o seu estilo de escrita, também seu livro pode ser lido como as memórias de um teólogo luterano que se vê a si mesmo como surpreendido diante da força persistente da religião no mundo moderno, apesar de sua confessada convicção religiosa pessoal. Mesmo para esse homem de "fé", a religiosidade contemporânea provocou surpresas. Contudo, mais importante, seu ensaio deve ser lido como a proposta de um novo programa de pesquisas tanto em sociologia da modernização quanto em sociologia da religião, onde a modernidade deixa de ser sinônimo de secularização e passa a ser sinônimo de pluralismo cultural e axiológico. E esta parece ser a principal herança intelectual deixada por Berger para as futuras gerações de estudiosos. Neste tempo em que grupos neonazistas, membros da Ku Klux Klan, Marcha pra Jesus e Parada Gay arrastam multidões e disputam lugares na esfera pública transnacional, o livro de Berger oferece mais do que uma outra versão de modernidade. Paradoxalmente, seu escrito é uma aposta de fé nas virtudes de uma reserva de secularidade em cada um dos "múltiplos altares" da modernidade. 


\section{Referências}

BERGER, Peter. The Desecularization of the World: Resurgent Religion and World Politics. Washington, DC, Ethics and Public Policy Center, 1999.

A Dessecularização do Mundo: uma visão global. Rio de Janeiro, Religião e Sociedade, 21 (1): 9-24, 2000.

. A construção social da realidade: tratado de sociologia do conhecimento. Petrópolis, Editora Vozes, 2008.

CORCUFF, Philippe. As Novas Sociologias: construções da realidade social. São Paulo, EDUSC, 2001.

DESOUSA FILHO, Alipio. Tudo é construído! Tudo é revogável! A teoria construcionista crítica nas ciências humanas. São Paulo, Editora Cortez, 2017.

DURKHEIM, Emile. Sociology and Philosophy. New York, Routledge, 2009.

JAMES, William. Varieties of Religious Experience. London and New York, Routledge, 2002.

JOAS, Hans. The Genesis of Values. Chicago, The University of Chicago Press, 2000.

Faith as Option: Possible Futures for Christianity. California, Stanford University Press, 2014.

SCHELER, Max. Ressentiment. USA, Marquette University Press, 1994.

TAYLOR, Charles. As Fontes do Self. São Paulo, Edições Loyola, 1997. Uma Era Secular. São Leopoldo, Editora Unisinos, 2010.

Recebido em 20/08/2017

Aprovado em 04/09/2017

\section{Como citar esta resenha:}

FREITAS, Carlos E. Adeus, secularismo! Bem-vindo, pluralismo! Rumo a um novo paradigma da modernidade? Contemporânea - Revista de Sociologia da UFSCar, v. 8, n. 1, jan.- jun. 2018, pp. 329-339. 